\title{
SHORT REPORT \\ Prescribing of neuraminidase inhibitors for influenza in UK primary care since the 2009 pandemic
}

\author{
P. HARDELID ${ }^{1,2} *$, G. RAIT ${ }^{3}$, R. GILBERT ${ }^{1}$ AND I. PETERSEN ${ }^{2,4}$ \\ ${ }^{1}$ Population, Policy and Practice Programme, UCL Institute of Child Health, London UK \\ ${ }^{2}$ Research Department of Primary Care and Population Health, University College London, London, UK \\ ${ }^{3}$ PRIMENT Clinical Trials Unit, Research Department of Primary Care and Population Health, University \\ College London, London, UK \\ ${ }^{4}$ Department of Clinical Epidemiology, Aarhus University, Aarhus, Denmark
}

Received 3 May 2015; Final revision 24 July 2015; Accepted 19 August 2015; first published online 14 September 2015

\section{SUMMARY}

We determined prescribing rates of neuraminidase inhibitors (NIs) for influenza in UK primary care since 2009 in relation to national prescribing guidelines. All NI prescriptions issued during the influenza seasons between October 2010 and May 2013 were extracted from The Health Improvement Network (THIN), a large UK primary-care database. We calculated NI prescribing rates per 100000 person-weeks (pw) by age group, sex, deprivation level, influenza season and presence of chronic conditions with $95 \%$ confidence intervals (CIs), and used negative binomial regression models to determine the independent association between these variables and NI prescribing. NI prescribing was rare. The prescribing rate was $1 \cdot 7 / 100000 \mathrm{pw}(95 \% \mathrm{CI} 1 \cdot 7-1 \cdot 8)$ during influenza-active periods, and $0 \cdot 1 / 100000(95 \%$ CI $0 \cdot 1-0 \cdot 1)$ during non-active periods. Prescribing rates were highest in 25- to 44-year-olds in 2010/2011 and in persons aged $\geqslant 85$ years in 2011/2012 and 2012/2013. Individuals with chronic conditions had significantly higher prescribing rates than persons without (rate ratio $2 \cdot 62,95 \%$ CI $2 \cdot 27-3 \cdot 03$ ). GPs are more likely to prescribe NIs to high-risk individuals and during influenza active periods, as per national guidelines. We could not assess the proportion of patients with influenza-like illness who were prescribed an NI.

Key words: Antimicrobial drugs, Influenza.

Neuraminidase inhibitors (NIs) are recommended for prophylaxis and treatment of seasonal influenza in a number of countries. In the UK, the National Institute for Health and Care Excellence (NICE) recommends NIs for treatment of influenza in patients presenting with influenza-like illness (ILI) in clinical risk groups during periods of active influenza

\footnotetext{
* Author for correspondence: Dr P. Hardelid, Population, Policy and Practice Programme, UCL Institute of Child Health, 30 Guilford Street, London WC1N 1EH, UK.

(Email: p.hardelid@ucl.ac.uk)
}

circulation. Patients aged $\geqslant 65$ years, or with chronic heart, renal, liver or neurological disease, diabetes or immunosuppression are considered to be at clinical risk. Treatment should commence within $48 \mathrm{~h}$ of onset [1]. NIs are also stockpiled in a number of countries for use in the wider population during pandemics. For example, the UK government spent $£ 560$ million on stockpiling NIs between 2006 and 2013 [2].

Despite these recommendations, the use of NIs remains controversial, especially in otherwise healthy individuals. A Cochrane Review of randomised 
controlled trials [3] showed that oseltamivir (Tamiflu) and zanamivir (Relenza) provided only modest reductions in symptom duration, with an increased risk of vomiting in both adults and children, and nausea, renal events, and headaches and psychiatric events in adults. It also concluded a lack of evidence of protection against laboratory-confirmed pneumonia, hospital admission or death.

NIs were widely prescribed in the UK during the 2009 influenza pandemic. There is little recent evidence regarding how often they are used in primary care outside a pandemic, the setting in which the majority of individuals with influenza symptoms who seek healthcare are likely to present. Here, we examine recent temporal and socio-demographic determinants of antiviral prescribing in UK primary care since the 2009 pandemic, to examine whether prescriptions are more likely to be issued to high-risk groups as recommended by NICE.

We used a large primary-care database, The Health Improvement Network (THIN), which includes anonymized longitudinal clinical and demographic data from over 500 general practices, covering approximately $6 \%$ of the UK population [4]. Prescriptions and diagnoses are entered in THIN by the general practitioner (GP, primary-care physician) during consultations. Diagnoses are entered using Read codes [5], and prescriptions using drug codes which map onto the British National Formulary [6]. THIN data collection has been approved by the South East NHS Multicentre Research Ethics Committee. The analyses for this study were approved by the Scientific Review Committee of the data providers.

Practices were included from the date on which they met quality criteria relating to data entry in THIN [7, 8]. We included all prescriptions of NIs issued in the study period (see below). In the UK, zanamivir is not licensed for children aged $<5$ years, and oseltamivir should only be used for children aged $<1$ year in exceptional circumstances with specialist supervision. We therefore included data on all patients aged 1-99 years inclusive. Person-time at risk was calculated from the start of the study period, 1 year after the date of registration with a THIN practice or the date the practice met data quality criteria (whichever was later), to the date of de-registration or death, the last day of the study period, or the last date the practice submitted data (whichever was earlier).

Influenza surveillance in the UK runs from week 40 in one year to week 20 in the next year (roughly, beginning of October to mid-May) [9]. We included the three winter seasons 2010/2011, 2011/2012 and 2012/2013. We estimated prescription rates during periods of active influenza circulation compared to non-active periods. Influenza-active periods are determined from surveillance data, and care providers are alerted through letters from the Chief Medical Officers (CMOs) in the four UK countries [10]. We used dates of letters from the English CMO announcing start and end dates of influenza activity to define influenza-active periods in THIN. The analysis assessing timing of prescribing was therefore limited to English practices only.

We determined whether individuals had a chronic condition, by searching for Read codes or prescriptions in their longitudinal primary-care records. We included immunosuppression, diabetes, neurological disease, respiratory disease (including asthma), liver disease, renal disease and heart disease as chronic conditions. To identify individuals with chronic conditions, we used diagnostic and drug code lists for defining clinical risk groups for influenza vaccination [11], and for the Quality and Outcomes Framework, a care monitoring system for individuals with chronic conditions in general practice [12]. Chronic condition status was determined at the start of each influenza season, by searching for chronic condition codes up to 1 year before the season start date.

We calculated total NI prescription rates per 100000 person-weeks ( $\mathrm{pw}$ ) by age group, sex, chronic condition status, deprivation (measured as quintiles of the Townsend score, a small area-based measure of deprivation) and influenza season. We used negative binomial regression models to examine the independent effect of these variables on NI prescription rates. Standard errors were calculated using robust methods in order to allow for between-practice variation. We examined whether the effect of age varied by season by including an interaction term between season and age group. We used Akaike's Information Criterion (AIC) to determine whether the addition of explanatory variables to the model improved the overall fit, and stratified the analyses by season where there was a significant interaction. We calculated practice-level NI prescribing rates and determined the inter-decile range (the difference between the 9th and the 1st decile) to examine between-practice variation in prescribing.

We also calculated the proportion of NI prescriptions which were made with an ILI code recorded, and the proportion that did not have a diagnosis code. ILI codes were identified using word searches of the Read code 
Table 1. Number of NI prescriptions, crude prescribing rates [per 100000 person-weeks ( $p w)$ ] (with 95\% CI) and adjusted prescribing rate ratios from negative binomial regression model (with 95\% CI), UK, 2010/2011 to 2012/2013

\begin{tabular}{|c|c|c|c|}
\hline & $\begin{array}{l}\text { No. of prescriptions } \\
\text { issued }\end{array}$ & $\begin{array}{l}\text { Prescribing rate per } \\
100000 \mathrm{pw}(95 \% \mathrm{CI})\end{array}$ & $\begin{array}{l}\text { Adjusted* prescribing } \\
\text { rate ratio }(95 \% \mathrm{CI})\end{array}$ \\
\hline \multicolumn{4}{|l|}{ Sex } \\
\hline Male & 1172 & $0 \cdot 7(0 \cdot 7-0 \cdot 7)$ & 1 (baseline) \\
\hline Female & 1806 & $1 \cdot 1(1 \cdot 0-1 \cdot 1)$ & $1 \cdot 43(1 \cdot 31-1 \cdot 56)$ \\
\hline \multicolumn{4}{|l|}{ Townsend quintile } \\
\hline 1st (least deprived) & 594 & $0.7(0 \cdot 6-0 \cdot 7)$ & 1 (baseline) \\
\hline 2nd & 571 & $0 \cdot 8(0 \cdot 7-0 \cdot 8)$ & $1 \cdot 07(0 \cdot 84-1 \cdot 36)$ \\
\hline $3 \mathrm{rd}$ & 626 & $0.9(0 \cdot 8-1 \cdot 0)$ & $1 \cdot 21(0.93-1 \cdot 58)$ \\
\hline 4 th & 572 & $0.9(0 \cdot 8-1 \cdot 0)$ & $1 \cdot 21(0 \cdot 95-1 \cdot 55)$ \\
\hline 5th (most deprived) & 615 & $1 \cdot 4(1 \cdot 3-1 \cdot 5)$ & $1 \cdot 82(1 \cdot 32-2 \cdot 52)$ \\
\hline \multicolumn{4}{|l|}{ Chronic condition } \\
\hline No & 1964 & $0 \cdot 7(0 \cdot 7-0 \cdot 7)$ & 1 (baseline) \\
\hline Yes & 1014 & $1 \cdot 7(1 \cdot 6-1 \cdot 8)$ & $2 \cdot 62(2 \cdot 27-3 \cdot 03)$ \\
\hline \multicolumn{4}{|c|}{ Influenza season $2010 / 2011$} \\
\hline $1-14$ years & 483 & $2 \cdot 6(2 \cdot 4-2 \cdot 9)$ & $1 \cdot 84(1 \cdot 52-2 \cdot 23)$ \\
\hline $15-24$ years & 383 & $2 \cdot 9(2 \cdot 6-3 \cdot 2)$ & $2 \cdot 11(1 \cdot 81-2 \cdot 45)$ \\
\hline $25-44$ years & 684 & $2 \cdot 2(2 \cdot 1-2 \cdot 4)$ & $1 \cdot 57(1 \cdot 36-1 \cdot 81)$ \\
\hline $45-64$ years & 475 & $1 \cdot 5(1 \cdot 3-1 \cdot 6)$ & 1 (baseline) \\
\hline $65-74$ years & 129 & $1 \cdot 2(1 \cdot 0-1 \cdot 4)$ & $0.71(0.55-0.91)$ \\
\hline $75-84$ years & 67 & $1 \cdot 0(0 \cdot 7-1 \cdot 2)$ & $0.53(0.41-0.68)$ \\
\hline $85-99$ years & 17 & $0 \cdot 6(0 \cdot 4-1 \cdot 0)$ & $0.33(0 \cdot 20-0 \cdot 56)$ \\
\hline \multicolumn{4}{|c|}{ Influenza season $2011 / 2012$} \\
\hline $1-14$ years & 5 & $0 \cdot 0(0 \cdot 0-0 \cdot 1)$ & $0.21(0.07-0.62)$ \\
\hline $15-24$ years & 12 & $0 \cdot 1(0 \cdot 0-0 \cdot 2)$ & $0.73(0.37-1 \cdot 44)$ \\
\hline $25-44$ years & 44 & $0 \cdot 1(0 \cdot 1-0 \cdot 2)$ & $1 \cdot 16(0.79-1.69)$ \\
\hline $45-64$ years & 42 & $0 \cdot 1(0 \cdot 1-0 \cdot 2)$ & 1 (baseline) \\
\hline $65-74$ years & 20 & $0 \cdot 2(0 \cdot 1-0 \cdot 3)$ & $1 \cdot 19(0 \cdot 66-2 \cdot 16)$ \\
\hline $75-84$ years & 28 & $0 \cdot 4(0 \cdot 3-0 \cdot 6)$ & $2 \cdot 45(1 \cdot 11-5 \cdot 40)$ \\
\hline $85-99$ years & 68 & $2 \cdot 5(2 \cdot 0-3 \cdot 2)$ & $14 \cdot 23(6 \cdot 40-31 \cdot 65)$ \\
\hline \multicolumn{4}{|c|}{ Influenza season $2012 / 2013$} \\
\hline $1-14$ years & 11 & $0 \cdot 1(0-0 \cdot 1)$ & $0 \cdot 18(0 \cdot 09-0 \cdot 38)$ \\
\hline $15-24$ years & 17 & $0 \cdot 1(0 \cdot 1-0 \cdot 2)$ & $0.41(0 \cdot 24-0 \cdot 70)$ \\
\hline $25-44$ years & 73 & $0 \cdot 3(0 \cdot 2-0 \cdot 3)$ & $0 \cdot 78(0 \cdot 55-1 \cdot 11)$ \\
\hline $45-64$ years & 104 & $0 \cdot 3(0 \cdot 3-0 \cdot 4)$ & 1 (baseline) \\
\hline $65-74$ years & 66 & $0.6(0 \cdot 5-0 \cdot 7)$ & $1 \cdot 52(1 \cdot 14-2 \cdot 04)$ \\
\hline $75-84$ years & 92 & $1 \cdot 4(1 \cdot 1-1 \cdot 7)$ & $3 \cdot 21(1 \cdot 96-5 \cdot 27)$ \\
\hline $85-99$ years & 158 & $6 \cdot 1(5 \cdot 2-7 \cdot 1)$ & $13 \cdot 51(6 \cdot 92-26 \cdot 37)$ \\
\hline
\end{tabular}

CI, Confidence interval.

* Sex, chronic condition status, Townsend quintile, influenza season, age group and an influenza season $\times$ age group interaction term were included in the model.

dictionary, and are listed in Supplementary Table S1. All analyses were performed with Stata version 13.0 [13].

The study included a total of 4200680 individuals in 505 general practices followed up from October 2010 to May 2013. Of the 4200680 individuals, 1251913 $(29 \cdot 8 \%)$ were aged between 1 and 24 years, 2262256 $(53.9 \%)$ between 25 and 64 years and $686511(16 \cdot 3 \%)$ were aged $\geqslant 65$ years. Half of the individuals were men $(2080653,49 \cdot 5 \%)$ and $20 \cdot 5 \%(861290)$ had a chronic condition during any of the three influenza seasons between 2010 and 2013. During the same period, 2978 NI prescriptions were issued of which 2866 $(96 \cdot 2 \%)$ were oseltamivir and $112(3 \cdot 8 \%)$ were zanamivir.

The prescription rate during influenza-active periods was $1 \cdot 7 / 100000 \mathrm{pw}(95 \%$ CI $1 \cdot 7-1 \cdot 8)$ and during non-active periods $0 \cdot 1 / 100000(95 \%$ CI $0 \cdot 1-0 \cdot 1)$. Of the 1730 prescriptions issued in English practices $1561(90 \cdot 2 \%)$ were issued during periods of active influenza circulation. 
The inter-decile range of practice-level consultation rates was $2 \cdot 25 / 100000 \mathrm{pw}(95 \%$ CI $0-2 \cdot 25 / 100000)$. The difference between the 9th and 1st decile of practice-level prescribing rates was therefore greater than the difference in prescribing during influenza-active and non-active periods.

An interaction term between age group and influenza season significantly improved the fit of the negative binomial regression model, implying that the age pattern of prescription rates varied significantly by season. In 2010/2011, the highest prescription rates were found in individuals aged $<25$ years; however, in the two following seasons, the highest rates were found in persons aged $\geqslant 85$ years (Table 1). Individuals with chronic conditions had prescription rates more than $2 \frac{1}{2}$ times those of individuals without (adjusted prescribing rate ratio $2 \cdot 62,95 \%$ CI $2 \cdot 27-3 \cdot 03$ ).

Only $1303(43 \cdot 8 \%)$ of the 2978 NI prescriptions had an accompanying diagnosis of ILI recorded, and 1425 $(47 \cdot 9 \%)$ had another diagnosis recorded. Supplementary Table S2 shows the ten most common Read codes recorded for patients with an ILI. Of the non-ILI diagnoses, the most common were 'cough', 'upper respiratory tract infection' and 'viral infection, not otherwise specified'. Other common Read codes entered referred to place of consultation, or administration; $8.3 \%$ of prescriptions had no diagnosis code recorded.

Since the influenza A(H1N1) pandemic in 2009, NI prescribing has been rare in UK primary care, with less than two prescriptions per 100000 people per week during influenza-active periods, during which $90 \%$ of the NI prescriptions were issued. Individuals aged $\geqslant 85$ years had the highest prescription rates in the two most recent seasons, as did individuals with chronic conditions, with very low prescribing rates (less than one prescription per 100000 persons per week) in other age and risk groups. Over half of all NI prescriptions did not have a diagnosis code indicating an ILI. Although overall prescribing rates were low, we identified substantial between-practice variation in prescribing.

Our large study of over 4 million individuals allowed robust comparisons between age groups and influenza seasons in NI prescribing. The study was limited to prescribing in primary care. Since there is no national hospital prescribing database in the UK, we could not assess NI prescribing in hospital settings. Further, we could not determine whether NIs were issued for prophylaxis or treatment as this is not coded in the patient's records. Since we did not have information on date of symptom onset, we could not assess whether the NICE criterion for timeliness of treatment was met.

We did not attempt to assess NI prescribing in persons presenting with ILI according to patient characteristics, since the denominator for such an analysis could not be readily determined. There is no standard case definition for ILI in UK primary care, and therefore ILI is not consistently recorded across GP practices. Indeed, $56 \%$ of prescriptions were issued to people without an ILI diagnosis recorded. We could therefore not determine whether patients with ILI who were high risk according to NICE criteria were equally likely to be prescribed NI treatment. Researchers using primarycare databases need to exercise caution when examining prescriptions in individuals selected based on recording of particular diagnoses.

Our results indicate that GPs are more likely to prescribe NIs to individuals in risk groups, with few prescriptions during influenza non-active periods. This is in accordance with national guidelines. We could not determine the probability of treatment in patients with ILI. Future studies should be undertaken to examine adherence to NI prescribing guidelines in secondary care.

\section{SUPPLEMENTARY MATERIAL}

For supplementary material accompanying this paper visit http://dx.doi.org/10.1017/S095026881500206X.

\section{ACKNOWLEDGEMENTS}

This work was supported by a National Institute for Health Research postdoctoral fellowship to P.H. (grant no. PDF-2013-06-004). This article represents independent research funded by the National Institute for Health Research (NIHR). The views expressed are those of the authors and not those of the NHS, the NIHR or the Department of Health. R.G. and P.H. are members of the Farr Institute of Health Informatics Research London. The sponsors had no role in study design, collection, analysis, interpretation of data, or writing of the report.

\section{DECLARATION OF INTEREST}

None.

\section{REFERENCES}

1. National Institute of Health and Clinical Excellence. Amantadine, oseltamivir and zanamivir for the treatment 
of influenza, 2009 (http://www.nice.org.uk/nicemedia/ pdf/TA168fullguidance.pdf). Accessed 6 September 2012.

2. House of Commons Public Accounts Committee. Access to clinical trial information and the stockpiling of Tamiflu, 2013 (http://www.publications.parliament.uk/pa/ cm201314/cmselect/cmpubacc/295/29502.htm). Accessed 22 July 2014.

3. Jefferson T, et al. Neuraminidase inhibitors for preventing and treating influenza in healthy adults and children. Cochrane Database of Systematic Reviews 2014; 4: CD008965.

4. CSD Medical Research. The Health Improvement Network, 2014 (http://csdmruk.cegedim.com/our-data/ our-data.shtml). Accessed: 16 April 2014.

5. Benson T. The history of the Read codes: the inaugural James Read Memorial Lecture 2011. Informatics in Primary Care 2011;19:173-182.

6. Joint Formulary Committee. British National Formulary 66. London: BMJ Group, 2014.

7. Horsfall L, Walters K, Petersen I. Identifying periods of acceptable computer usage in primary care research databases. Pharmacoepidemiology and Drug Safety 2013; 22: 64-69.
8. Maguire A, Blak BT, Thompson M. The importance of defining periods of complete mortality reporting for research using automated data from primary care. Pharmacoepidemiology and Drug Safety 2009; 18: 76-83.

9. Public Health England. Surveillance of influenza and other respiratory viruses, including novel respiratory viruses, in the United Kingdom: winter 2012/2013. 2013 (http://www.hpa.org.uk/webc/HPAwebFile/HPA web_C/1317139321787). Accessed 25 Ocober 2013

10. NHS Central Alerting System. Influenza season 2013/ 14 - use of antiviral medicines, 2013 (https://www.cas. dh.gov.uk/ViewandAcknowledgment/ViewAlert.aspx? AlertID=102108). Accessed 29 October 2014.

11. PRIMIS. Specification document for the Seasonal Influenza Immunisation Vaccine Uptake Monitoring Programme 2013/14. 2013 (http://www.primis.nottingham. ac.uk/index.php/news/hot-news/849). Accessed 9 January 2014.

12. Health and Social Care Information Centre. Quality and Outcomes Framework - 2012-13. 2013 (http://www.hscic. gov.uk/catalogue/PUB12262). Accessed 10 October 2014

13. StataCorp. Stata Statistical Software: release 13. College Station, TX: StataCorp LP, 2013. 